\title{
Thickness-Controllable Silica Coating of CdTe QDs by Reverse Microemulsion Method for the Application in the Growth of Rice
}

\author{
Aiwu Wang, ${ }^{1,2}$ Yuhong Zheng, ${ }^{1}$ and Feng Peng ${ }^{1}$ \\ ${ }^{1}$ Institute of Botany, Jiangsu Province and Chinese Academy of Sciences, Nanjing Botanical Garden, Memorial Sun Yat-Sen, \\ Nanjing 210014, China \\ ${ }^{2}$ Department of Physics and Materials Science and Centre for Functional Photonics (CFP), City University of Hong Kong, \\ 88 Tat Chee Avenue, Kowloon, Hong Kong
}

Correspondence should be addressed to Yuhong Zheng; friend266@163.com

Received 3 May 2014; Accepted 28 May 2014; Published 15 June 2014

Academic Editor: Qingrui Zhang

Copyright (C) 2014 Aiwu Wang et al. This is an open access article distributed under the Creative Commons Attribution License, which permits unrestricted use, distribution, and reproduction in any medium, provided the original work is properly cited.

Herein, we report the synthesis and surface modification of CdTe quantum dots (QDs) and the application in the rice growth. Water-soluble thioglycolic acid (TGA) stabilized CdTe quantum dots were synthesized firstly and then the surface modification was conducted. II-VI semiconductor nanocrystals prefer to be coated with silica as inert materials to improve their chemical properties. The toxicity of QDs reduced after the modification. Silica coated QDs were used in the growth of rice seed and the effect was discussed. In our knowledge it is the first time we report that the silica coated QDs had nice effect on the growth of rice.

\section{Introduction}

Colloidal II-VI semiconductor nanocrystals (quantum dots) have shown nice size-dependent optical properties with narrow bandgap [1] like CdS [2], CdSe [3], CdTe [4], CdHgTe [5], HgTe [6], and $\mathrm{ZnSe}$ [7] which exhibit great potential as a labeling material due to their unique size-tunable photoluminescence. In the past 20 years, great progress has been made in the synthesis of the quantum dots, and the quantum dots have applications for fluorescent biological research [8-12].

However, QDs have disadvantages in their applications: toxicity due to the heavy metal ions [13], the chemical stabilities, and oxidation in the surface area. To solve these problems, coating QDs with inert materials like silica would be a good choice [14]. Silica coating of semiconductor nanocrystals has received specific effects [15-17]. The methods of silica coating can be divided into two groups, that is, the reverse microemulsion method and Stober method. For the aqueous QDs, the reverse microemulsion (water in oil) can be used in silica coating with better controlling of particle size than the Stober method. As for the Stober method, the silica sphere is usually large as $200 \mathrm{~nm}$ and bigger. By the reverse microemulsion method, the particle size can be controlled in a range of $30-150 \mathrm{~nm}$ [18] so that the reverse microemulsion method is more suitable. In our reported work, not only $40 \mathrm{~nm}$ of silica coating can be synthesized but also $400 \mathrm{~nm}$ of silica coating can be synthesized by the reverse microemulsion method.

In the past ten years, nanotechnology and nanomaterials were widely applied as life science [19]. But the research about their applications in agriculture began relatively late. Some work reported that silver nanoparticles reduced bacterial contaminations during tissue culture of Araucaria excelsa var. Glauca [20]; multiwall carbon nanotubes (MWNTs) had the ability to enhance the proliferation of callus cells of tobacco (Nicotiana tabacum) and make tomato produce two times more flowers and fruits $[21,22] ; \mathrm{TiO}_{2}$ and MWNTs significantly promoted the germination, seedlings growth of tomato (Lycopersicon esculentum), and spinach (Spinacia oleracea) $[23,24]$. Khodakovskaya et al. even illustrated 
MWNTs have the potential to act as plant growth regulators [22]. Some results proved several kinds of nanomaterials had the positive effects at every stage of plant life cycle and showed great capacity to regulate the plant growth and development. We investigated that silica coated CdTe QDs had good effects on the rice root growth.

\section{Experimental Section}

2.1. Chemicals. $\mathrm{Cd}\left(\mathrm{CH}_{3} \mathrm{COO}\right)_{2} * 2 \mathrm{H}_{2} \mathrm{O}$ (Aldrich, 99\%), tetraethyl orthosilicate (TEOS) (98\%), thioglycolic acid (TGA) (98\%), sodium hydroxide, polyoxyethylene octyl phenyl ether (TritonX-100), cyclohexane, n-hexanol, ethanol, and ammonium solution were purchased from Sigma-Aldrich.

2.2. Synthesis of CdTe QDs Stabilized by Thioglycolic Acid. CdTe QDs were synthesized according to the method reported previously [25]. First of all, $0.08 \mathrm{mmol}$ of $\mathrm{Na}_{2} \mathrm{TeO}_{3}$, $0.4 \mathrm{mmol}$ of $\mathrm{Cd}\left(\mathrm{CH}_{3} \mathrm{COO}\right)_{2} * 2 \mathrm{H}_{2} \mathrm{O}$, and $160 \mathrm{mg}$ of $\mathrm{NaBH}_{4}$ were prepared. Secondly, the $\mathrm{Cd}\left(\mathrm{CH}_{3} \mathrm{COO}\right)_{2} * 2 \mathrm{H}_{2} \mathrm{O}$ was dissolved in $50 \mathrm{~mL}$ deionized water and then poured into a flask with a magnetic bar. The solution was kept stirring. After that $100 \mathrm{~mL}$ of deionized water was added followed by the $36 \mu \mathrm{L}$ of TGA into the flask. Then the $\mathrm{pH}$ of the solution was adjusted to 11.5 by $2 \mathrm{M} \mathrm{NaOH}$ (several drops); next the $\mathrm{Na}_{2} \mathrm{TeO}_{3}$ was dissolved in $50 \mathrm{~mL}$ deionized water. After 5 minutes, $\mathrm{Na}_{2} \mathrm{TeO}_{3}$ with $\mathrm{NaBH}_{4}$ was added to the solution; other five minutes later, the flask was connected to a reflux condenser and through the opening at $100^{\circ} \mathrm{C}-$ up to 1 to 7 hours under air conditions. Finally, after cooling the filtered solution was poured into the bottle and stored in $4^{\circ} \mathrm{C}$ without washing.

2.3. Synthesis of Silica Coated CdTe QDs. Silica coated QDs were prepared according to previous reports by the reverse microemulsion method [16]. In detail, $4 \mathrm{~mL}$ of the solution prepared CdTe QDs was washed one time by $4 \mathrm{~mL}$ of isopropanol. The microemulsion solution was combined by $15 \mathrm{~mL}$ of cyclohexane, $2.25 \mathrm{~mL}$ of Triton X-100, and $1.5 \mathrm{~mL}$ of n-hexanol under the $\mathrm{N}_{2}$ atmosphere for half an hour (solution 1). Then $40 \mu \mathrm{L}$ of ammonia solution ( $25 \%$ by weight) was introduced and several drops of $1 \mathrm{M} \mathrm{NaOH}$ were added to make the $\mathrm{pH}$ to 12 (solution 2). The washed CdTe QDs dissolved in $1 \mathrm{~mL}$ of solution 2 (solution 3 ). Then the solution 3 was introduced into the prepared solution 1 (microemulsion liquid system). After 10 minutes of stirring, fixed amount of PDDA was introduced. $200 \mu \mathrm{L}$ TEOS was introduced under vigorous magnetic stirring. The reaction system was then sealed and kept in the dark; mixture was stirred at room temperature for 3 days. Isopropanol, ethanol, and water were used for washing the CdTe @ silica composite particles. In each washing process, a sonicator was needed. Firstly the ratio 1:1 with isopropanol was centrifuged; after that the precipitate was dissolved in the ethanol and deionized water. Finally CdTe @ silica composite particles were dissolved in the deionized water stored in $4^{\circ} \mathrm{C}$.

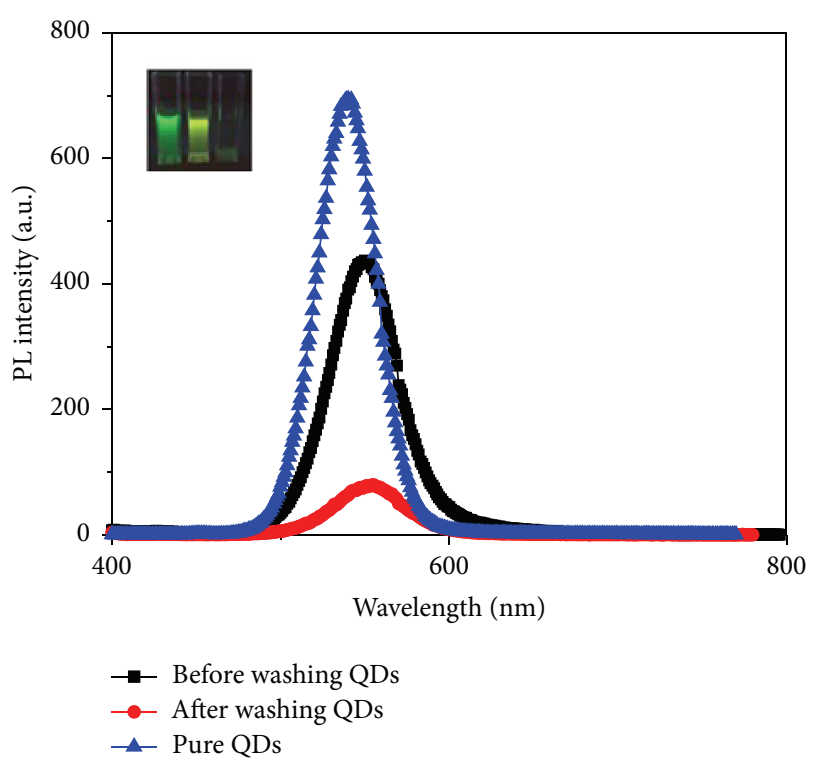

FIGURE 1: Fluorescence spectra of pure uncoated QDs, silica coated before washing QDs, and silica coated after washing QDs.

2.4. Rice Seed Germination and Root Development. Rice (Oryza sativa cv. 'Nanjing 45') seeds were immersed in a $0.1 \%$ potassium permanganate $\left(\mathrm{KMnO}_{4}\right)$ solution for $24 \mathrm{~h}$ for sterilization. After rinsing three times with deionized water, the seeds were soaked in $100 \mathrm{~mL} \mathrm{1/2} \mathrm{MS} \mathrm{solution} \mathrm{with} \mathrm{silica}$ coated QDs suspensions at various concentrations $(0.13 \mu \mathrm{M}$, $0.26 \mu \mathrm{M}$, and $0.52 \mu \mathrm{M})$ in thermostat incubator $\left(25 \pm 1^{\circ} \mathrm{C}\right.$, $60 \% \mathrm{rH}$, and 16/8 light/day) for germination, which $1 / 2 \mathrm{MS}$ with no silica coated QDs was used as a control. The root length was measured at 8,11 , and 15 days after treatment. Each treatment was conducted with thirty seeds, and the results were presented as increasing percent of ten seedlings root length average from 8 to 11 and 11 to 15 days.

2.5. Characterizations. Steady-state photoluminescence (PL) spectra were measured on an Edinburgh Instrument FLS920P fluorescence spectrometer. TEM machine model used for the images of $\mathrm{CdTe} @ \mathrm{SiO}_{2}$ is Philips-CM20 with the operation voltage $200 \mathrm{kV}$.

\section{Results and Discussion}

3.1. Silica Coating of CdTe QDs and Thickness Controlling. The fluorescence spectra and particles before and after silica coating were shown below in Figure 1.

After the reverse microemulsion method, the silica coated QDs are oil-soluble. After being washed in the ethanol and water, water-soluble silica coated QDs were available. After the washing, the amounts of QDs reduced so that the PL intensity decreased.

Transmission electron microscopy (TEM) images of silica coated QDs sample were presented in Figure 2.

As Figure 2 showed the nice effect with the coating is spherical and uniform. The chemical properties of QDs may 


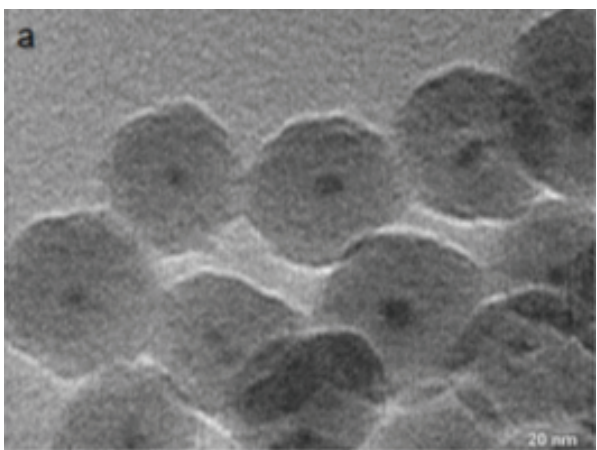

(a)

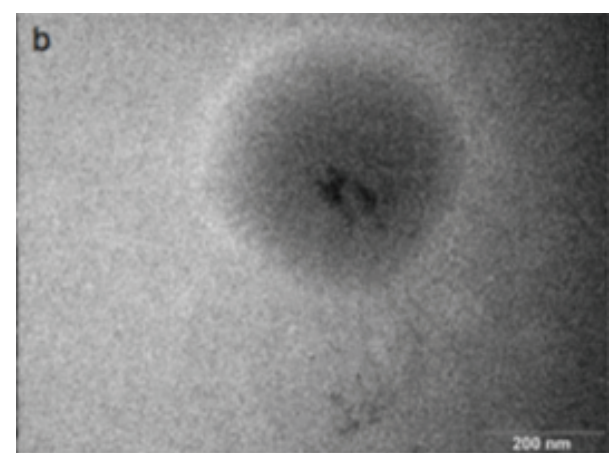

(b)

FIGURE 2: TEM images of samples of good silica coating of QDs under the suitable adjustment of conditions. (a) The size of silica is $40 \mathrm{~nm}$; (b) the size of silica is $400 \mathrm{~nm}$.

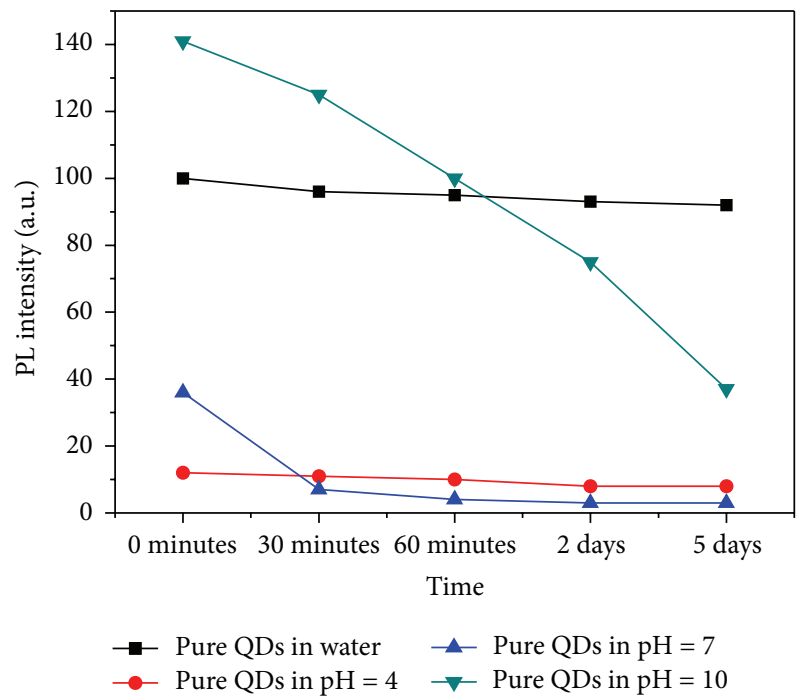

FIGURE 3: PL spectra of pure QDs in the different buffers tested for different times.

be better and also the stability. What is more, we can adjust the thickness of silica coating by controlling the amount of TEOS; the thickness of the silica coating is as large as $400 \mathrm{~nm}$ in comparison to the previous $40 \mathrm{~nm}$.

\subsection{Stability Test between the Pure Uncoated QDs and Silica} Coated QDs. The pure CdTe and silica coated after washing CdTe QDs were tested for stability in water and the buffers with different $\mathrm{pH}$ (4, 7, and 10 corresponding) for 4 days. Results are presented in Figure 3 for uncoated samples and in Figure 5 for silica coated.

From Figure 3 we can realize that the pure QDs in the water are stable, in the buffer with $\mathrm{pH}=10$ had an increase of PL than that of in the water, in the buffers with $\mathrm{pH}=7$ and $\mathrm{pH}=4$ are of low PL compared to that of in the water. What is more, the buffer with $\mathrm{pH}=4$ can quench the QDs in a short time, which implied that the QDs are sensitive to the $\mathrm{pH}$ of solution.

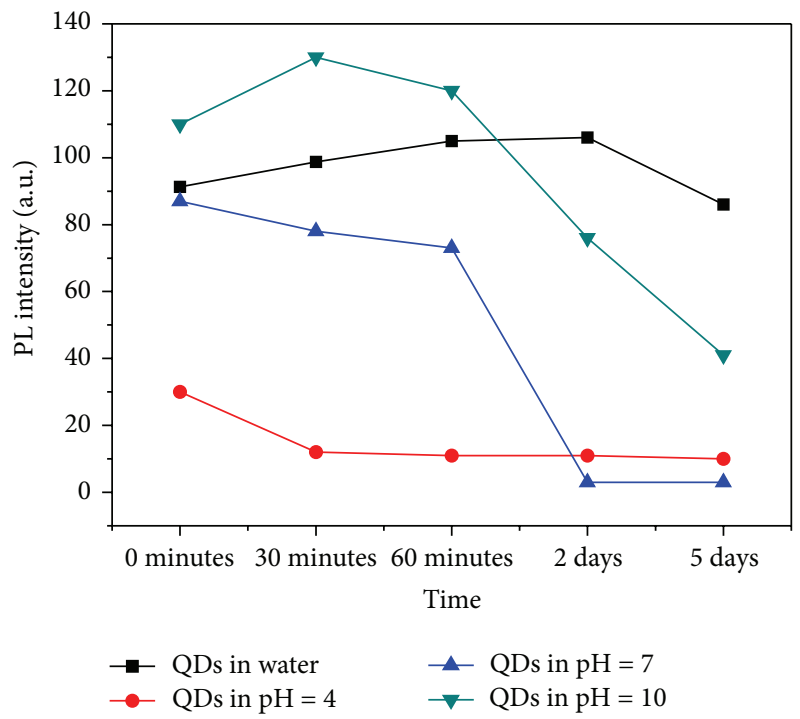

FIGURE 4: PL spectra of silica coating of QDs in the different buffers tested for different times.

From Figure 4 we can observe that the PL of silica coated QDs in the buffer with $\mathrm{pH}=10$ had a slight increase at first compared to the pure uncoated QDs in the $\mathrm{pH}=10$. And the PL of silica coated QDs in the buffer with $\mathrm{pH}=7$ had a higher increase than the pure QDs in the $\mathrm{pH}=7$. And the $\mathrm{PL}$ of silica coated QDs in the buffer with $\mathrm{pH}=4$ was slightly higher than the pure uncoated QDs. With the good effect we can infer that the stability of silica coated QDs is better than the pure uncoated QDs.

3.3. Rice Seed Germination and Root Development. Each treatment was conducted with thirty seeds, and the results are presented as increasing percent of ten seedlings root length average from 8 to 11 and 11 to 15 days.

As we can observe from Figure 5 that the rice roots with silica coated QDs were longer than the rice roots without silica coated QDs inside. The pure QDs significantly inhibited the growth of root due to its toxicity. The different increment 

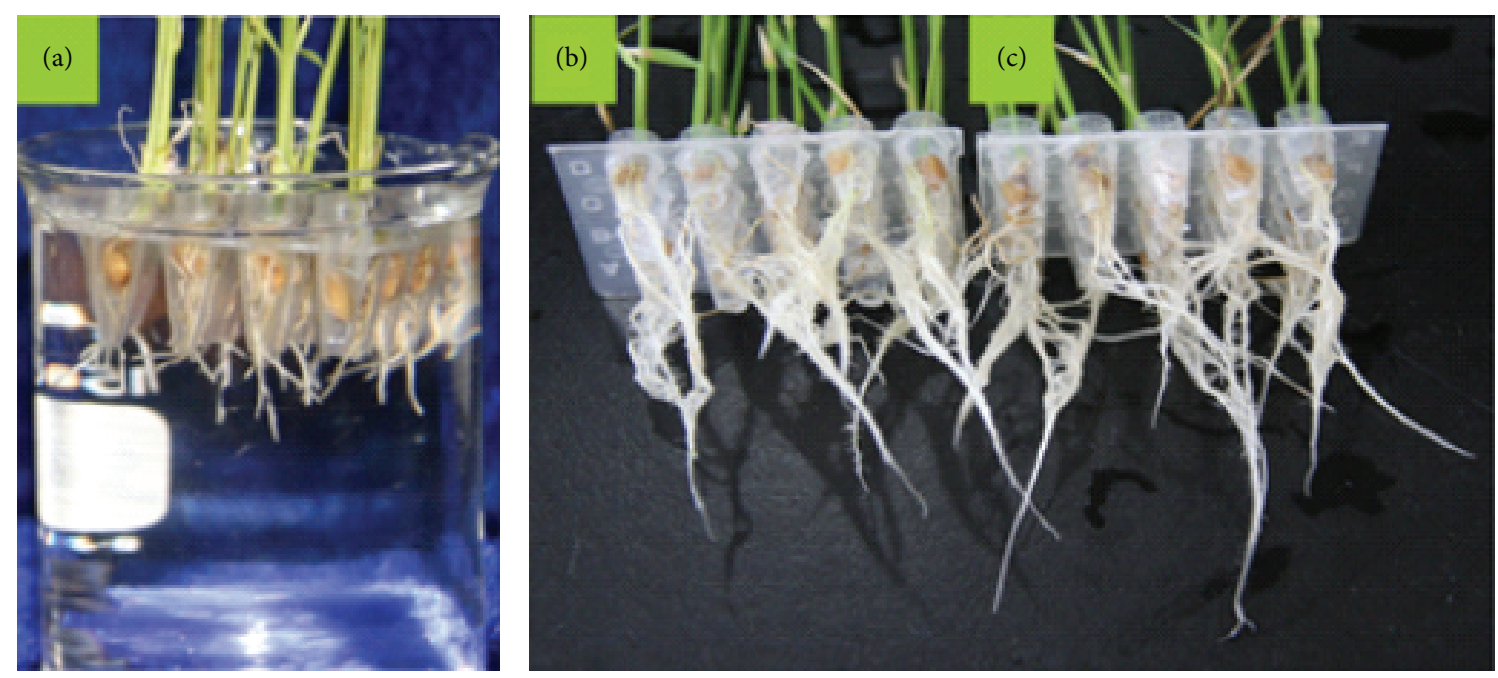

FIgURE 5: Image of rice roots (a) with pure QDs; (b) without QDs; and (c) with silica coated QDs.

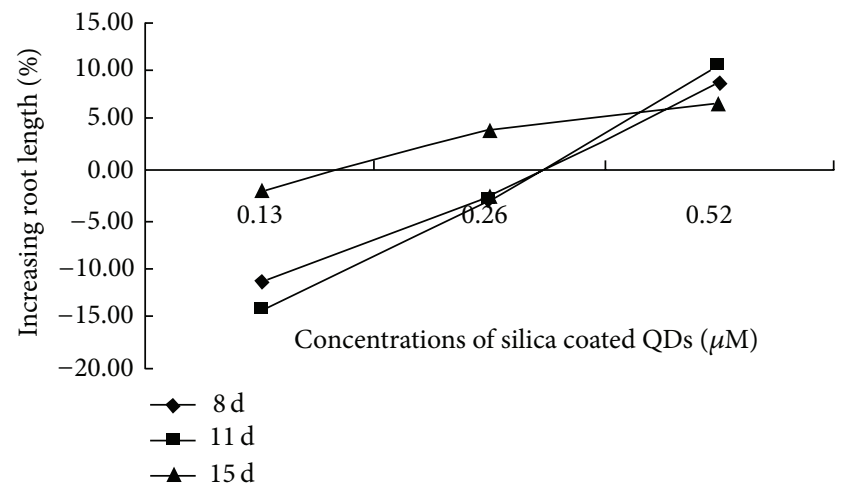

FIGURE 6: Effects of silica coated QDs at different concentrations on rice root length.

of different concentrations of silica coated QDs was shown below as Figure 6.

To test the action of the synthesized silica coated QDs, we placed the seeds in 1/2 Murashige and Skoog solution supplemented with different concentrations of silica coated QDs $(0.13 \mu \mathrm{M}, 0.26 \mu \mathrm{M}$, and $0.52 \mu \mathrm{M})$. As shown in Figures 5 and 6 , all the treatments led to the growth of the increasing percent of root length. Silica coated CdTe QDs did not have toxic effect but promoted root elongation of rice seedlings. The roots grew faster in shorter time under low concentrations. The results were different from many other researches about the nanomaterials affecting the plant growth [26-29]. Many investigations in the past were negative mainly due to the toxicity of nanoparticles. For example, $\mathrm{TiO}_{2}$ nanoparticles significantly inhibited the germination rates, root lengths, and biomasses of tobacco seedlings [30]. Iron ions/NPs did not affect the physiological parameters with respect to water control. Conversely, $\mathrm{Cu}$ ions/NPs reduced water content, root length, and dry biomass of the lettuce plants [31]. Toxicity of $\mathrm{CuO}$ NPs was mainly due to NPs solubilization in the media [32]. However, there are some nanoparticles that can promote the growth of plant. Iron nanoparticles can enhance root elongation of arabidopsis thaliana by triggering cell wall loosening [33]. Silica coated QDs are minority nanomaterials that are helpful in the growth of plants. And the mechanism needs to be further studied.

\section{Conclusion}

Silica coating of CdTe QDs particles has successfully been prepared by a reverse microemulsion method and the thickness of silica sphere can be varied from $40 \mathrm{~nm}$ to $440 \mathrm{~nm}$. The amount of TEOS is critical for the experiments. The stability test was made which approved the better stability of silica coated QDs than pure uncoated QDs. At last the $40 \mathrm{~nm}$ size of silica coated CdTe QDs had good effect on the rice roots growth for the first time reported.

\section{Conflict of Interests}

The authors declared that there is no conflict of interests regarding the publication of this paper.

\section{Acknowledgments}

The authors thank the support from Institute of Botany, Jiangsu Province, and Chinese Academy of Sciences, Nanjing Botanical Garden.

\section{References}

[1] M. Bruchez Jr., M. Moronne, P. Gin, S. Weiss, and A. P. Alivisatos, "Semiconductor nanocrystals as fluorescent biological labels," Science, vol. 281, no. 5385, pp. 2013-2016, 1998.

[2] T. Vossmeyer, L. Katsikas, M. Giersig et al., "CdS nanoclusters: synthesis, characterization, size dependent oscillator strength, temperature shift of the excitonic transition energy, and reversible absorbance shift," Journal of Physical Chemistry, vol. 98, no. 31, pp. 7665-7673, 1994. 
[3] A. L. Rogach, A. Kornowski, M. Gao, A. Eychmüller, and H. Weller, "Synthesis and characterization of a size series of extremely small thiol-stabilized CdSe nanocrystals," Journal of Physical Chemistry B, vol. 103, no. 16, pp. 3065-3069, 1999.

[4] A. L. Rogach, L. Katsikas, A. Kornowski et al., "Synthesis and characterization of thiol-stabilized CdTe nenocrystals," Berichte der Bunsengesellschaft für Physikalische Chemie, vol. 100, no. 11, pp. 1772-1778, 1996.

[5] M. T. Harrison, S. V. Kershaw, M. G. Burt, A. Eychmüller, H. Weller, and A. L. Rogach, "Colloidal nanocrystals for telecommunications complete coverage of the low-loss fiber windows by mercury telluride quantum dots," Materials Science and Engineering B, vol. 335, pp. 69-70, 2000.

[6] A. Rogach, S. Kershaw, M. Burt et al., "Optical properties of semiconductor nanostructures," Advanced Materials, vol. 11, pp. 552-555, 1999.

[7] A. Shavel, N. Gaponik, and A. Eychmüller, "Efficient UV-blue photoluminescing thiol-stabilized water-soluble alloyed $\mathrm{ZnSe}$ (S) nanocrystals," Journal of Physical Chemistry B, vol. 108, no. 19, pp. 5905-5908, 2004.

[8] M. Green, "Semiconductor quantum dots as biological imaging agents," Angewandte Chemie International Edition, vol. 43, no. 32, pp. 4129-4131, 2004.

[9] X. Gao, Y. Cui, R. M. Levenson, L. W. K. Chung, and S. Nie, "In vivo cancer targeting and imaging with semiconductor quantum dots," Nature Biotechnology, vol. 22, no. 8, pp. 969976, 2004.

[10] K. J. Jaiswal and M. S. Sanford, "Potentials and pitfalls of fluorescent quantum dots for biological imaging," Trends in Cell Biology, vol. 14, no. 9, pp. 497-504, 2004.

[11] D. Gerion, F. Pinaud, S. C. Williams et al., "Synthesis and properties of biocompatible water-soluble silica-coated CdSe/ZnS semiconductor quantum dots," Journal of Physical Chemistry B, vol. 105 , no. 37, pp. 8861-8871, 2001.

[12] W. C. W. Chan and S. Nie, "Quantum dot bioconjugates for ultrasensitive nonisotopic detection," Science, vol. 281, no. 5385, pp. 2016-2018, 1998.

[13] A. M. Derfus, W. C. W. Chan, and S. N. Bhatia, "Probing the cytotoxicity of semiconductor quantum dots," Nano Letters, vol. 4, no. 1, pp. 11-18, 2004.

[14] S. T. Selvan, T. T. Tan, and J. Y. Ying, "Robust, non-cytotoxic, silica-coated CdSe quantum dots with efficient photoluminescence," Advanced Materials, vol. 17, no. 13, pp. 1620-1625, 2005.

[15] A. L. Rogach, D. Nagesha, J. W. Ostrander, M. Giersig, and N. A. Kotov, "Raisin bun'-type composite spheres of silica and semiconductor nanocrystals," Chemistry of Materials, vol. 12, no. 9, pp. 2676-2685, 2000.

[16] Y. H. Yang and M. Y. Gao, "Preparation of fluorescent $\mathrm{SiO}_{2}$ particles with single CdTe nanocrystal cores by the reverse microemulsion method," Advanced Materials, vol. 17, no. 19, pp. 2354-2357, 2005.

[17] T. Nann and P. Mulvaney, "Single quantum dots in spherical silica particles," Angewandte Chemie International Edition, vol. 43, no. 40, pp. 5393-5396, 2004.

[18] S. Chang, L. Liu, and S. A. Asher, "Preparation and properties of tailored morphology, monodisperse colloidal silica-cadmium sulfide nanocomposites," Journal of the American Chemical Society, vol. 116, no. 15, pp. 6739-6744, 1994.

[19] C. Bai, "Ascent of nanoscience in China," Science, vol. 309, no. 5731, pp. 61-63, 2005.
[20] M. Sarmast, H. Salehi, and M. Khosh-Khui, "Nano silver treatment is effective in reducing bacterial contaminations of Araucaria excelsa R. Br. var. glauca explants," Acta Biologica Hungarica, vol. 62, no. 4, pp. 477-484, 2011.

[21] M. V. Khodakovskaya, K. de Silva, A. S. Biris, E. Dervishi, and H. Villagarcia, "Carbon nanotubes induce growth enhancement of tobacco cells," ACS Nano, vol. 6, no. 3, pp. 2128-2135, 2012.

[22] M. V. Khodakovskaya, B. S. Kim, J. N. Kim et al., "Carbon nanotubes as plant growth regulators: effects on tomato growth, reproductive system, and soil microbial community," Small, vol. 9, no. 1, pp. 115-123, 2013.

[23] L. Zheng, F. S. Hong, S. P. Lu, and C. Liu, "Effect of nano$\mathrm{TiO}_{2}$ on strength of naturally aged seeds and growth of spinach," Biological Trace Element Research, vol. 104, no. 1, pp. 83-91, 2005.

[24] M. V. Khodakovskaya, E. Dervishi, M. Mahmood et al., "Carbon nanotubes are able to penetrate plant seed coat and dramatically affect seed germination and plant growth," ACS Nano, vol. 3, no. 10, pp. 3221-3227, 2009.

[25] S. Wu, J. Dou, J. Zhang, and S. Zhang, "A simple and economical one-pot method to synthesize high-quality water soluble CdTe QDs," Journal of Materials Chemistry, vol. 22, no. 29, pp. 1457314578, 2012.

[26] A. Menard, D. Drobne, and A. Jemec, "Ecotoxicity of nanosized $\mathrm{TiO}_{2}$. Review of in vivo data," Environmental Pollution, vol. 159, no. 3, pp. 677-684, 2011.

[27] Q. M. Peng, J. X. Guo, Q. R. Zhang, A. G. Zhou, and Y. J. Tian, "Unique lead adsorption behavior of activated hydroxyl group in two-dimensional titanium carbide," Journal of the American Chemical Society, vol. 136, no. 11, pp. 4113-4116, 2014.

[28] Q. Zhang, Q. Du, M. Hua, T. Jiao, F. Gao, and B. Pan, “Sorption enhancement of lead ions from water by surface charged polystyrene-supported nano-zirconium oxide composites," Environmental Science and Technology, vol. 47, no. 12, pp. 6536-6544, 2013.

[29] Q. Zhang, Q. Du, T. Jiao et al., "Rationally designed porous polystyrene encapsulated zirconium phosphate nanocomposite for highly efficient fluoride uptake in waters," Scientific Reports, vol. 3, article 2551, 2013.

[30] T. P. Frazier, C. E. Burklew, and B. Zhang, "Titanium dioxide nanoparticles affect the growth and microRNA expression of tobacco (Nicotiana tabacum)," Functional \& Integrative Genomics, vol. 14, no. 1, pp. 75-83, 2014.

[31] J. Trujillo-Reyes, S. Majumdar, C. E. Botez, J. R. Peralta-Videa, and J. L. Gardea-Torresdey, "Exposure studies of core-shell $\mathrm{Fe} / \mathrm{Fe}_{3} \mathrm{O}_{4}$ and $\mathrm{Cu} / \mathrm{CuO}$ NPs to lettuce (Lactuca sativa) plants: are they a potential physiological and nutritional hazard?" Journal of Hazardous Materials, vol. 267, pp. 255-263, 2014.

[32] F. Perreault, R. Popovic, and D. Dewez, "Different toxicity mechanisms between bare and polymer-coated copper oxide nanoparticles in Lemna gibba," Environmental Pollution, vol. 185, pp. 219-227, 2014.

[33] J.-H. Kim, Y. Lee, E.-J. Kim et al., "Exposure of iron nanoparticles to arabidopsis thaliana enhances root elongation by triggering cell wall loosening," Environmental Science \& Technology, vol. 48, no. 6, pp. 3477-3485, 2014. 

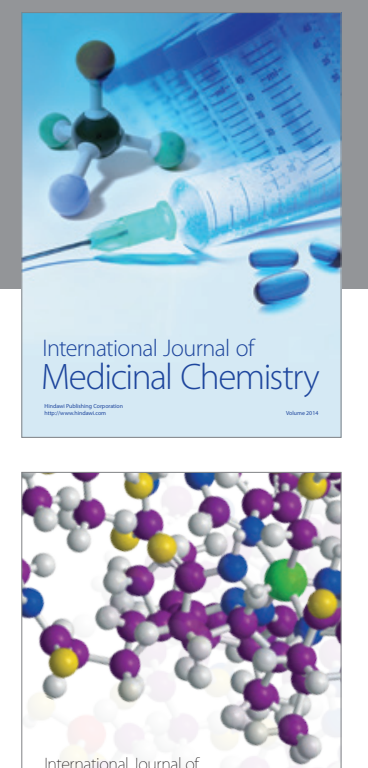

\section{Carbohydrate} Chemistry

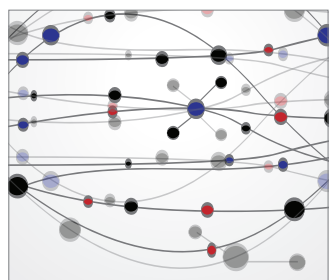

The Scientific World Journal
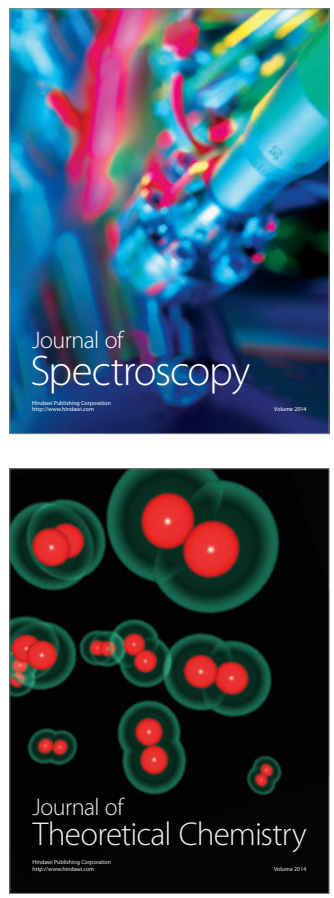
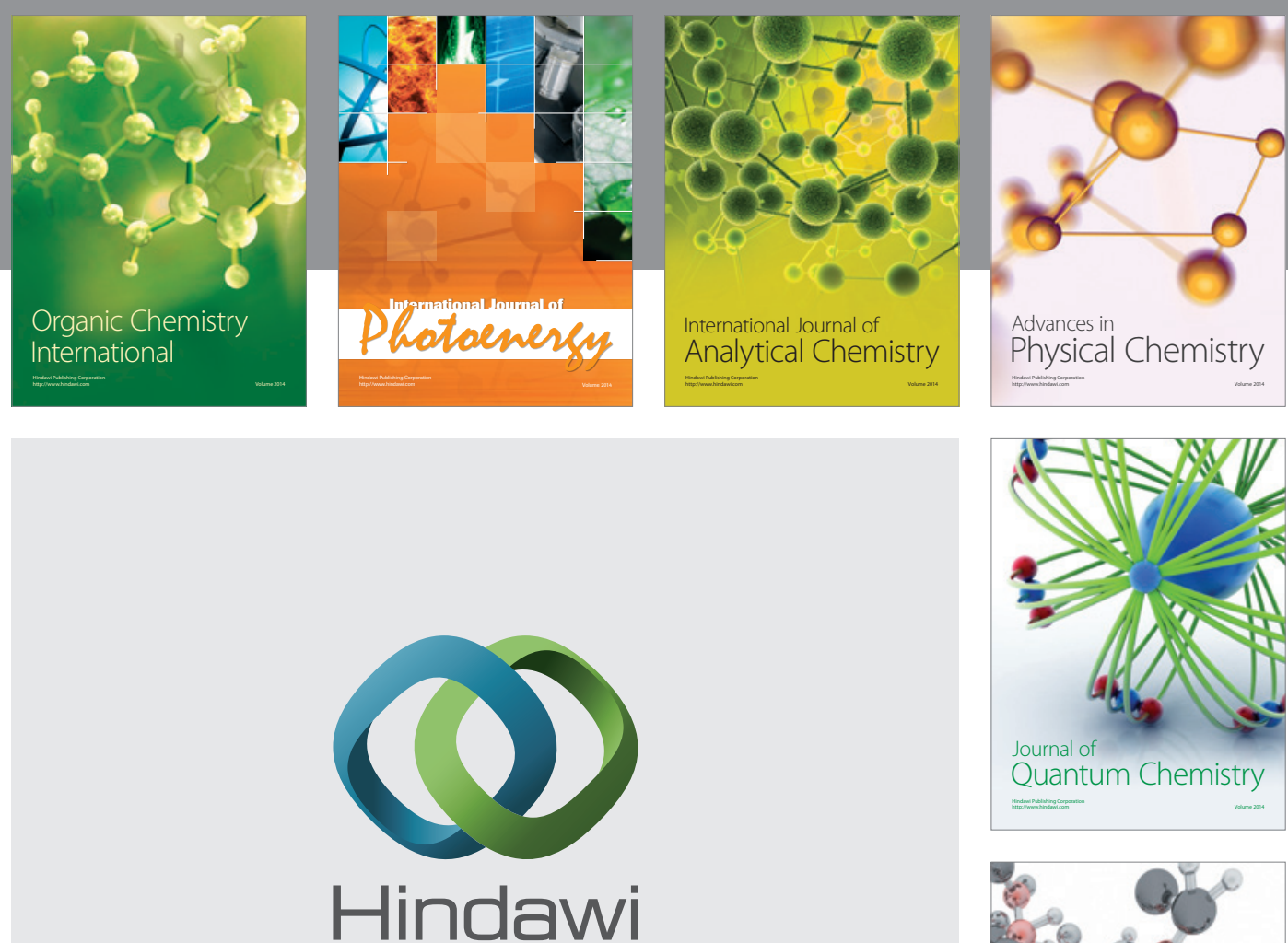

Submit your manuscripts at

http://www.hindawi.com

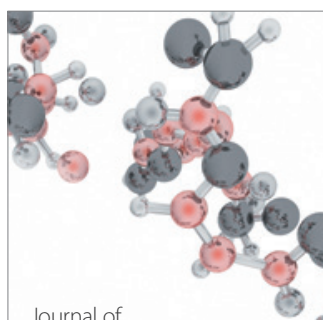

Analytical Methods

in Chemistry

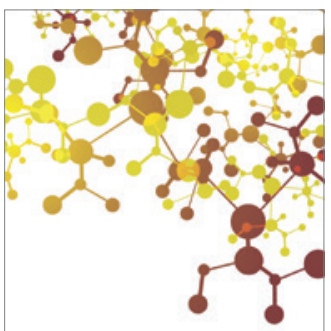

Journal of

Applied Chemistry

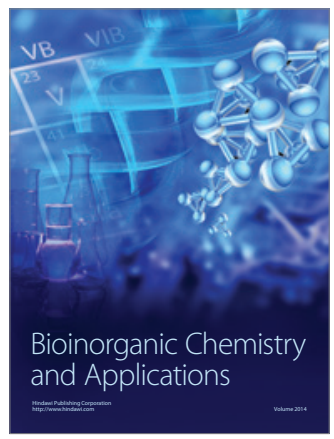

Inorganic Chemistry
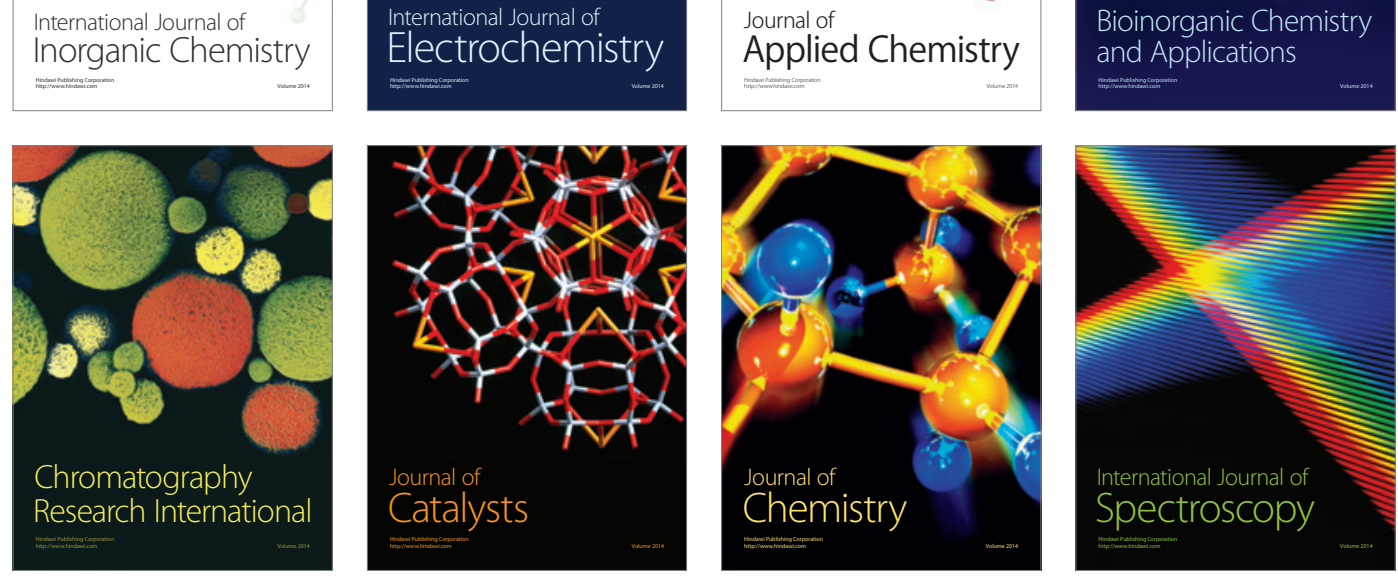